\title{
Lipomatous hypertrophy of interatrial septum
}

\author{
Konstantinos M Lampropoulos, ${ }^{1,2}$ Dimitrios Kotsas, ${ }^{1}$ Themistoklis lliopoulos $^{2}$ \\ ${ }^{1}$ Department of Cardiology, Polyclinic General Hospital of Athens, Greece \\ ${ }^{2}$ Department of Cardiology, 251 General Air Force Hospital of Athens, Greece
}

Correspondence to Dr Konstantinos M Lampropoulos, konlampropoulos@yahoo.gr

\begin{abstract}
Summary
Lipomatous hypertrophy of the interatrial septum is being increasingly recognised and should be considered as part of the differential diagnosis for any cardiac tumour. We present the case of a 65-year-old male patient who presented at the emergency department complaining of palpitations. Transthoracic and transoesophageal echocardiography detected a lipomatous membrane separating the dilated left atrium from the right atrium. Diagnosis was confirmed by MRI. In such cases, the opinion of a specialist echocardiologist would help to avoid a misdiagnosis and unnecessary intervention.
\end{abstract}

\section{BACKGROUND}

In such cases, the opinion of a specialist echocardiologist would help to avoid a misdiagnosis and unnecessary intervention.

\section{INTRODUCTION}

Lipomatous hypertrophy of the interatrial septum (LHIS) is a benign cardiac mass characterised as a nonencapsulated mass of fatty tissue that infiltrates the atrial septum first described in $1964 .{ }^{1}$ Although once described as a relatively rare finding, with the widespread use of echocardiography lipomatous hypertrophy is now being increasingly recognised and should be considered as part of the differential diagnosis for any atrial cardiac tumour. As most patients with this condition remain asymptomatic, the majority of cases are generally picked up as an incidental finding at the time of cardiac imaging, surgery or necropsy.

It is typically detected in patients older than 50 years and is more common in women. It is characterised by the excessive deposition of fat in the interatrial septum and a thickness of $>2 \mathrm{~cm}^{2}$ Former case reports indicate that LHIS usually occurs in elderly, obese patients. ${ }^{3}$ Reports have described the characteristics of LHIS on CT scans and MRI, apart from echocardiography, and this is now considered a well-described cardiac lesion. Although in most cases LHIS is not clinically apparent, it may cause right atrial obstruction (usually at the level of superior vena cava inlet), intractable arrhythmias or even sudden cardiac death. It is thus, a potentially serious condition that should not go undetected by the attending physician, and poses a challenge for pathologists whenever receiving a cardiac mass for evaluation in a patient with a history of sudden death due to an unidentified cause.

\section{CASE PRESENTATION}

This is the case of a 65-year-old male patient who presented at the emergency department (ED) complaining of palpitations. He had a history of acute myocardial infarction 7 years ago and paroxysmal atrial fibrillation for which he has been on standard oral anticoagulation.
At the initial evaluation at the ED an ECG revealed atrial fibrillation with heart rate ranging from 70 to 100 beats/min. Chest x-ray demonstrated an enlarged heart size, specially due to left atrium. Transthoracic and transoesophageal echocardiography detected a lipomatous membrane separating the dilated left atrium from the right atrium. (figure $1 \mathrm{~A}-\mathrm{C}$ ) Transoeosophageal echocardiography also revealed the presence of the above-stated diaphragm in the left atrium as well as echogenic hypertrophy of the interatrial septum (about $2 \mathrm{~cm}$ ), sparing the foramen ovale (figure $1 \mathrm{D}-\mathrm{F}$ ). Diagnosis was confirmed by MRI of the chest and the anatomic substance at the level of interatrial septum was defined as fat (figures $1 \mathrm{G}, \mathrm{H}$ ). After his investigation and the optimisation of his medical treatment, the benign nature of the atrial septal lesion was explained to the patient and he was discharged with local follow-up.

\section{DIFFERENTIAL DIAGNOSIS}

Lipomatous hypertrophy of the interatrial septum is being increasingly recognised and should be considered as part of the differential diagnosis for any cardiac tumour.

\section{DISCUSSION}

Primary cardiac tumours are rare and the great majority are benign neoplasms. Mass-forming reactive and pseudoneoplastic growths are less common, but recognising and distinguishing these lesions from the neoplasms they resemble is critical to appropriate patient care. Tumours of the heart, whether neoplastic or not, are infrequently encountered in surgical or autopsy pathology. ${ }^{4}$ Their scarcity and the spectrum of lesions spanning reactive conditions, and both benign and malignant neoplasms, often generate considerable diagnostic difficulty.

LHIS is a process involving the limbus of the fossa ovalis, a structure representing the embryological septum secundum. During embryogenesis, the right and left atria are divided by progressive in-folding of the roof and upper anterior/posterior walls of the rudimentary common chamber along the midline. Mesodermal tissues are drawn into the wall of the primitive atrial septum during this process and pockets of entrapped adipose tissue remain 


\section{BMJ Case Reports}

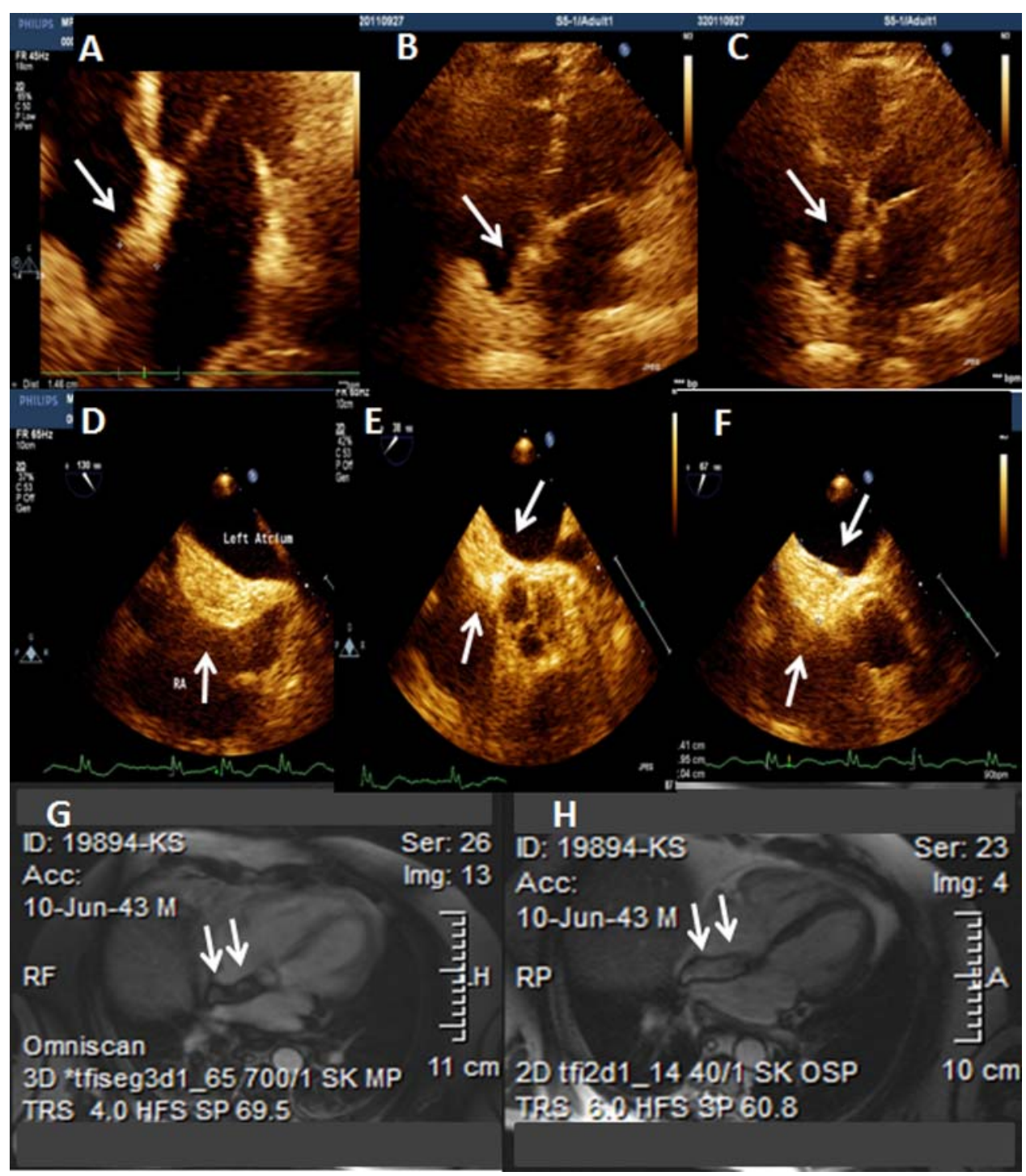

Figure 1 Arrows $(A-C)$, transthoracic echocardiogram showing lipomatous hypertrophy of the interatrial septum (LHIS). Arrows (D-F), transoesophageal echocardiogram showing LHIS. Arrows $(\mathrm{G}, \mathrm{H})$, MRI confirmed the diagnosis of LHIS.

after the heart is fully formed. In some patients, through as-of-yet undetermined processes (presumably the same ones governing this phenomenon in epicardial fat), the entrapped adipose tissue expands, resulting in bulging of the atrial septum, that can become more than 15 or $20 \mathrm{~mm}$ thick. ${ }^{4}$ This is most prominent in the right atrium (since the limbus is a right atrial structure). This process seems to be age dependent ${ }^{5}$ and there is a weak association with obesity. ${ }^{6}$ The valve of the fossa ovalis and membranous atrioventricular septum are not involved by LHIS. ${ }^{7}$

When encountered in an autopsy, explant or rare surgical pathology specimens, the gross appearance is the same as fatty tissue anywhere, though there may be more pronounced fine fibrous trabeculae. Microscopically, there is no capsule and both mature and brown fat may be seen. Entrapped atrial cardiomyocytes may be present and often show marked hypertrophic changes. These should not be mistaken for lipoblasts or cells of liposarcoma. Typically, epicardial structures such as nerve ganglion can also be seen in these lesions. Singly distributed hypertrophic myocytes can show significant nuclear pleomorphism and hyperchromasia.

The incidence of LHIS is not precisely known. Although the diagnosis of LHIS is rarely made during a person's lifetime, due to a lack of typical clinical symptoms, autopsy findings have suggested that the lesion is far more common. The reported incidence of LHIS at autopsy is about $1 \%$, whereas transthoracic echocardiography studies revealed incidences of up to $8 \%{ }^{8}$

In 1982, the first patient was presented in whom the diagnosis of LHIS had been established during life by the use of CT scanning. ${ }^{10}$ Even conventional CT scanning is able to depict the exact morphology of LHIS, including its characterisation as fatty. Still, multislice CT scanning represents an enormous technical advance compared with the conventional spiral CT scanning. By acquiring multiple sequences simultaneously, shorter data acquisition times, greater coverage, decreased number of motion artefacts and improved sharpness of images can be achieved. Furthermore, isotropic data sets provide the opportunity to reconstruct images in every axis, thus providing a 
precise three-dimensional evaluation of cardiovascular morphology.

It has been suspected that LHIS is typically associated with obesity and advancing age, whereas some authors have reported that it predominates in women. ${ }^{11} 12$ The diagnosis of LHIS is most commonly made incidentally. In 1969, Kluge observed that the presence of LHIS can cause arrhythmia. Since then, some case reports have shown that LHIS might lead to a variety of rhythm disturbances such as P-wave abnormalities (an abnormal P-wave configuration in leads II, III, aVF has been described, 'dome and dip'), atrial fibrillation and even sudden death. ${ }^{13} 14$ Malignant cardiac arrhythmias may occur as a result of extensive bleeding into the lesion. The mechanism of how LHIS causes cardiac rhythm abnormalities is still unknown, and a clear cause-and-effect relationship has not yet been established. Nevertheless, arrhythmia in LHIS may be due to atherosclerotic coronary artery disease, a common finding in affected patients. In addition, it is suspected that the involvement of the interatrial septum and the wall of the right atrium, especially in patients with large lesions, interferes with the architecture of atrial myocytes, which could affect conducting pathways. ${ }^{2}$

LHIS presents with characteristic features in imaging studies. It derives exclusively from the upper and/or lower part of the interatrial septum with typical sparing of the foramen ovale, giving the lesion the characteristic dumbbell shape. As already mentioned, the first in vivo descriptions of LHIS were made by echocardiography, a diagnostic method not able to differentiate between fat and connective tissue. Furthermore, the use of transthoracic ultrasound in patients with LHIS may be limited due to the presence of accompanying emphysema, which was noted in $64 \%$ of patients in one study. ${ }^{2}$ This association would result in restricted acoustic access to mediastinal structures with consequent diminished image quality and decreased sensitivity for the detection of LHIS with conventional transthoracic echocardiography. This might explain why a substantial percentage of patients with LHIS are missed in transthoracic echocardiographic studies.

The differentiation of LHIS from other cardiac neoplasms based on conventional imaging findings might be difficult. Myxomas are the most common primary cardiac tumours, accounting for $30-50 \%$ of all cases. ${ }^{15}$ The majority of myxomas are solitary and are located in the atria. They arise from the interatrial septum in the vicinity of the foramen ovale, whereas the foramen ovale is always spared in LHIS. Furthermore, most myxomas are pedunculated on a fibrovascular stalk, thus differentiating it from LHIS. Cardiac lipoma is a true neoplasm occurring in younger patients. Lipomas are encapsulated, which is never seen in LHIS. Rhabdomyomas and fibromas are common cardiac tumours in infants and children, and usually occur in the ventricles. Cardiac liposarcoma, a rare entity that predominantly appears in the right atrium, is a rapidly growing tumour with early signs of local invasion and haemodynamic comprise. Intraseptal cardiac liposarcomas have never been described. Cardiac metastases are much more common than primary cardiac tumours and may occur in any of the cardiac chambers. ${ }^{15}$ Their incidence is high in malignant melanoma, lymphoma and leukaemia, in which they occur in the setting of extensive disease. It should also be noted that LHIS can be associated with metabolic disorders such as cerebrotendinous xanthomatosis ${ }^{16}$ or mediastino-abdominal lipomatosis. ${ }^{17}$ Another predisposing factor for developing LHIS is a long-term parenteral nutrition, which determines the need for screening those patients. Our case demonstrated that the diagnosis can be made based on transthoracic and transoeosophageal echocardiography. Although diagnosis confirmed by MRI, this test remains an expensive technique localised to specialist centres.

\section{CONCLUSION}

With the general population mean age ever increasing, the world obesity epidemic rampaging and the constant improvement and availability of medical imaging techniques, the diagnosis of LHIS is bound to become more frequent. There is a clear scope for combining imaging modalities, with echocardiography being the first technique to provide evidence of the disease and then multislice CT or MRI delineating further the preliminary findings, ${ }^{18}$ as was the case in the history of our patient. Thus, LHIS is an easy-to-diagnose disease that could be the culprit for a number of seemingly 'lone' conditions, like atrial fibrillation. Clinical vigilance is warranted if we want to provide the best medical practice for our patients.

\section{Learning points}

- With the general population mean age ever increasing, the world obesity epidemic rampaging and the constant improvement and availability of medical imaging techniques, the diagnosis of lipomatous hypertrophy of the interatrial septum (LHIS) is bound to become more frequent.

- There is a clear scope for combining imaging modalities, with echocardiography being the first technique to provide evidence of the disease and then multislice CT or MRI delineating further the preliminary findings, ${ }^{18}$ as was the case in the history of our patient. Thus, LHIS is an easy-to-diagnose disease that could be the culprit for a number of seemingly 'lone' conditions, like atrial fibrillation. Clinical vigilance is warranted if we want to provide the best medical practice for our patients.

\section{Competing interests None.}

Patient consent Obtained.

\section{REFERENCES}

1. O'Connor S, Recavarren R, Nichols LC, et al. Lipomatous hypertrophy of the interatrial septum: an overview. Arch Pathol Lab Med 2006;130:397-9.

2. Heyer CM, Kagel T, Lemburg SP, et al. Lipomatous hypertrophy of the interatrial septum: a prospective study of incidence, imaging findings, and clinical symptoms. Chest 2003;124:2068-73.

3. Nadra I, Dawson D, Schmitz SA, et al. Lipomatous hypertrophy of the interatrial septum: a commonly misdiagnosed mass often leading to unnecessary cardiac surgery. Heart 2004;90:e66.

4. Bhattacharjee $\mathbf{M}$, Neligan MC, Dervan P. Lipomatous hypertrophy of the interatrial septum: an unusual intraoperative finding. Br Heart $\mathrm{J}$ 1991;65:49-50.

5. Burke AP, Litovsky S, Virmani R. Lipomatous hypertrophy of the atrial septum presenting as a right atrial mass. Am J Surg Pathol 1996;20:678-85. 


\section{BMJ Case Reports}

6. Beau $\mathbf{P}$, Michel P, Coisne D, et al. Lipomatous hypertrophy of the cardiac interatrial septum: an unusual complication in long-term home parenteral nutrition in adult patients. JPEN J Parenter Enteral Nutr 1991;15:659-62.

7. Simons M, Cabin HS, Jaffe CC. Lipomatous hypertrophy of the atrial septum: diagnosis by combined echocardiography and computerized tomography. Am J Cardiol 1985;54:465-6.

8. Xanthos T, Giannakopoulos N, Papadimitriou L. Lipomatous hypertrophy of the interatrial septum: a pathological and clinical approach. Int J Cardiol 2007;121:4-8.

9. Pochis WT, Saeian K, Sagar KB. Usefulness of transesophageal echocardiography in diagnosing lipomatous hypertrophy of the atrial septum with comparison to transthoracic echocardiography. Am J Cardiol 1992;70:396-8.

10. Isner JM, Swan CS II, Mikus JP, et al. Lipomatous hypertrophy of the interatrial septum: in vivo diagnosis. Circulation 1982;66:470-3.

11. Burke AP, Litovsky S, Virmani R. Lipomatous hypertrophy of the atrial septum presenting as a right atrial mass. Am J Surg Pathol 1996:20:678-85.

12. Shirani J, Roberts WC. Clinical, electrocardiographic and morphologic features of massive fatty deposits ("lipomatous hypertrophy") in the atrial septum. J Am Coll Cardiol 1993;22:226-38.
13. Hutter AM, Page DL. Atrial arrhythmias and lipomatous hypertrophy of the cardiac interatrial septum. Am Heart J 1971;82:16-21.

14. Gay JD, Guileyardo JM, Townsend-Parchman JK, et al. Clinical and morphologic features of lipomatous hypertrophy ("massive fatty deposits") of the interatrial septum. Am J Forensic Med Pathol 1996;18:107-8.

15. Novick RJ, Dobell ARC. Tumors of the heart. In: Baue EA Thoracic and cardiovascular surgery. 5th edn. East Norwalk, CT: 1989-2002 Appleton and Lange, 1991.

16. Dotti MT, Mondillo S, Plewnia K, et al. Cerebrotendinous xanthomatosis: evidence of lipomatous hypertrophy of the right atrium. J Neurol 1998;245:723-6.

17. Enzi G, Busetto L, Ceschin E, et al. Multiple symmetric lipomatosis: clinical aspects and outcome in a long-term longitudinal study. Int J Obes Relat Metab Disord 2002;26:253-61.

18. Bassareo PP, Tumbarello R, Mercuro G. Cor triatriatum and lipomatous hypertrophy of the interatrial septum in the elderly: a case report. Cardiovasc Ultrasound 2010;8:4.

This pdf has been created automatically from the final edited text and images.

Copyright 2012 BMJ Publishing Group. All rights reserved. For permission to reuse any of this content visit http://group.bmj.com/group/rights-licensing/permissions.

BMJ Case Report Fellows may re-use this article for personal use and teaching without any further permission.

Please cite this article as follows (you will need to access the article online to obtain the date of publication).

Lampropoulos KM, Kotsas D, lliopoulos T. Lipomatous hypertrophy of interatrial septum. BMJ Case Reports 2012;10.1136/bcr-2012-006611, Published XXX

Become a Fellow of BMJ Case Reports today and you can:

- Submit as many cases as you like

- Enjoy fast sympathetic peer review and rapid publication of accepted articles

- Access all the published articles

- Re-use any of the published material for personal use and teaching without further permission

For information on Institutional Fellowships contact consortiasales@bmjgroup.com

Visit casereports.bmj.com for more articles like this and to become a Fellow 